\title{
Integrated Studies for Mapping of Uranium Mineralization in Northern Cape Province of South Africa
}

\author{
Bijay Kumar Mishra, N. Sulekha Rao \\ Natural Resource Division, RMSI Private Limited, Hyderabad, India \\ Email: bijay.mishra@rmsi.com, sulekha.rao@rmsi.com
}

Received 30 June 2015; accepted 2 August 2015; published 5 August 2015

Copyright (C) 2015 by authors and Scientific Research Publishing Inc.

This work is licensed under the Creative Commons Attribution International License (CC BY). http://creativecommons.org/licenses/by/4.0/

(c) (i) Open Access

\begin{abstract}
Globally, there has been an ever increasing demand for uranium. This generates the need to adopt unique methodologies in order to explore the mineral to its full extent. This paper highlights an integrated approach that is adopted to explore uranium occurrences in the Northern Cape Province of South Africa. The study area is located at Springbok of Namaqualand Region. Most of the area is dominated by smooth outcrops formed by "Woolsack" mode of weathering and is characterized by pinkish fine-grained concordia granites of fair size forming the hilly terrains. These granites were intruded by quartz and pegmatite veins which host uranium and associated ores. As part of the integrated approach, remote sensing, geological, geophysical and geochemical studies were carried out in the hilly terrain area of approximately $15 \mathrm{sq} \mathrm{km}$ area. Spectral analysis was carried out using ASTER and QuickBird imageries to identify the zones of mineralisation. Band combinations of $R$ (5/8) G (4/6) B (6/7) revealed the occurrence of uranium ore in the study area. Remote sensing and geological studies prioritized area for geophysical and geochemical studies. Ground magnetic analytical signal maps helped in deciphering the sub-surface structural anomalies. Magnetic and radiometric studies revealed that the uranium mineralization was localized along the structural features which were of sub-surficial origin. Geochemical sampling helped to identify the zones with high uranium ore concentration along the structural trend of the area. Further, geochemical data analysis also strongly supported the geophysical data and showed that the host rocks contain mineable quantities of uranium. The above integrated study indicates that uranium mineralisation in this particular area is structurally controlled which is nothing but the manifestations of geological features such as faults, fissures, and joints. The study helped to identify two blocks covering $85 \mathrm{Ha}$ and $174 \mathrm{Ha}$ of area and $\mathbf{7 d r i l l i n g}$ locations were proposed for exploratory drilling.
\end{abstract}

\section{Keywords}

Uranium, Remote Sensing, Geological, Geophysical, Geochemical, Magnetometer, Spectrometer 


\section{Introduction}

Nowadays uranium exploration studies are at its surge due to increasing demand of the mineral as it plays a very important role in the development of national economy and national defense.

The present study is concentrated in a block located in the Urafields Projects in South Africa. This is situated in the Namaqualand Springbok area of Northern Cape Province.

There are three main types of uranium mineralization occurring in Southern Africa viz. alaskite deposits, fluvial pale channel type deposits and granite deposits. These uranium deposits occur in two metamorphic complexes, the Damara Orangic Belt in Namibia and the Namaqua-Natal Matamorphic Complex in South Africa.

Previous studies (in 1070's and 1970's) showed that radiometric surveys and geological mapping of Namaqualand area resulted in the discovery of a number of late-stage leuco-granitic intrusions in close proximity to the margins of the concordia granites.

Several methodologies [1]-[7] for uranium exploration have been attempted in the past to define the formation, alteration and enrichment of uranium deposits. But to successfully extract such strategic deposits, an integrated exploration technique is needed which will provide important references to radioactive ore-body disposition. Thus in the present exploration study, an integrated and interpretative approach of geospatial studies, regional geological setting, geochemical anomaly and geophysical data is considered to decipher geoenvironmental information hosting uranium ore mineralization. Remote sensing and geological mapping help to define probable zones of radioactive mineralization while in the current methodology geochemical and geophysical datasets are the pioneering techniques in confirming good concentrations of sub-surface occurrences of ore bodies.

\section{Study Area}

The study area of 1536 hectare (Figure 1) is located in the Northern Cape Province of South Africa. The study area lies in a deep low plain lying between rugged mountains of high granite domes at an altitude of 3300 feet (1000 m), about $600 \mathrm{~km}$ north of Cape Town.

\section{Geological Setting of the Area}

The study area block falls in Paleo-Mesoproterozoic Namaqua-Natal sector (Figure 2) in Northern Cape Province of South Africa.

The Natal Sector is composed of three terranes, the Tugela, Mzumbe and Margate Terranes, small crustal blocks separated by tectonic boundaries. The terranes in the Natal Sectors are made up of essentially juvenile arc sequences, related marine sediments and arc-root granitic to gabbroic intrusions The Namaqua Sector is composed of six different terranes and subprovinces. The Namaqua Sector is composed of NNW-SSE, NW to SE and finally EW oriented terranes. Their orientation corresponds to the regional fabric in each terrane [8]-[10].

\section{Materials and Methods}

\subsection{Satellite Data}

\subsubsection{ASTER (Advanced Space Borne Thermal Emission and Reflection Radiometer)}

ASTER satellite data having 14 bands (Table 1) with each scene covering an area of $3600 \mathrm{sq}$ km are effectively used for geological mapping and detecting the subtle variations in the minerals. Range of bands in ASTER data is a valuable asset in geological studies and field management.

\subsubsection{QB (QuickBird)}

QuickBird is a high resolution satellite owned and operated by Digital Globe. QuickBird imaging capabilities can be applied to a host of industries including mineral, oil and gas exploration, production (E \& P), engineering and construction and environmental studies. The specifications of QB data were provided in Table 2.

\subsection{Satellite Remote Sensing Studies}

Remote sensing studies were carried out using ASTER images for geological mapping of the study area block to understand the lithological units and structural features which favors the occurrence of uranium mineralization. Geological interpretations were carried out based on the spectral signatures obtained using ASTER data which 


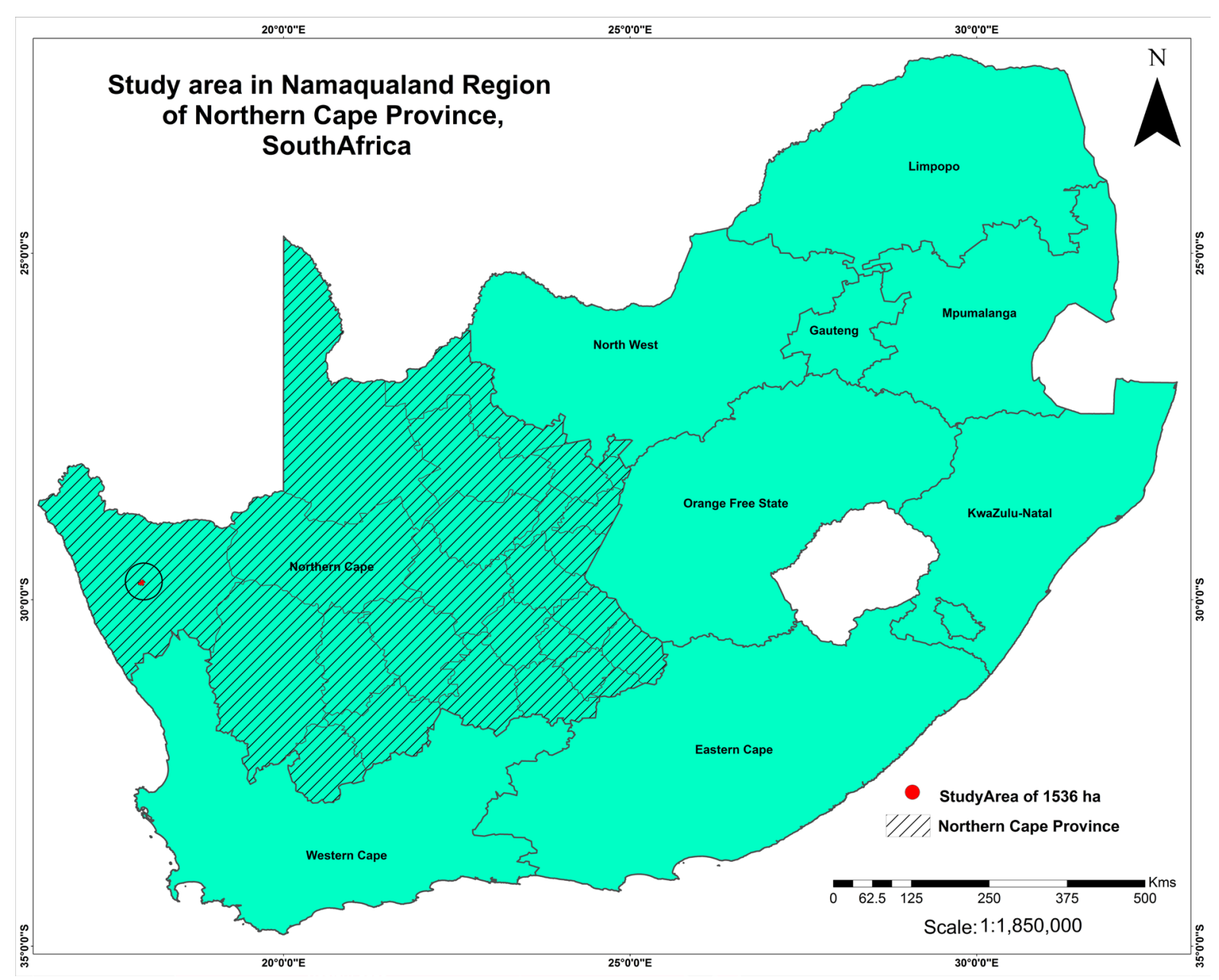

Figure 1. Study area block in South Africa.

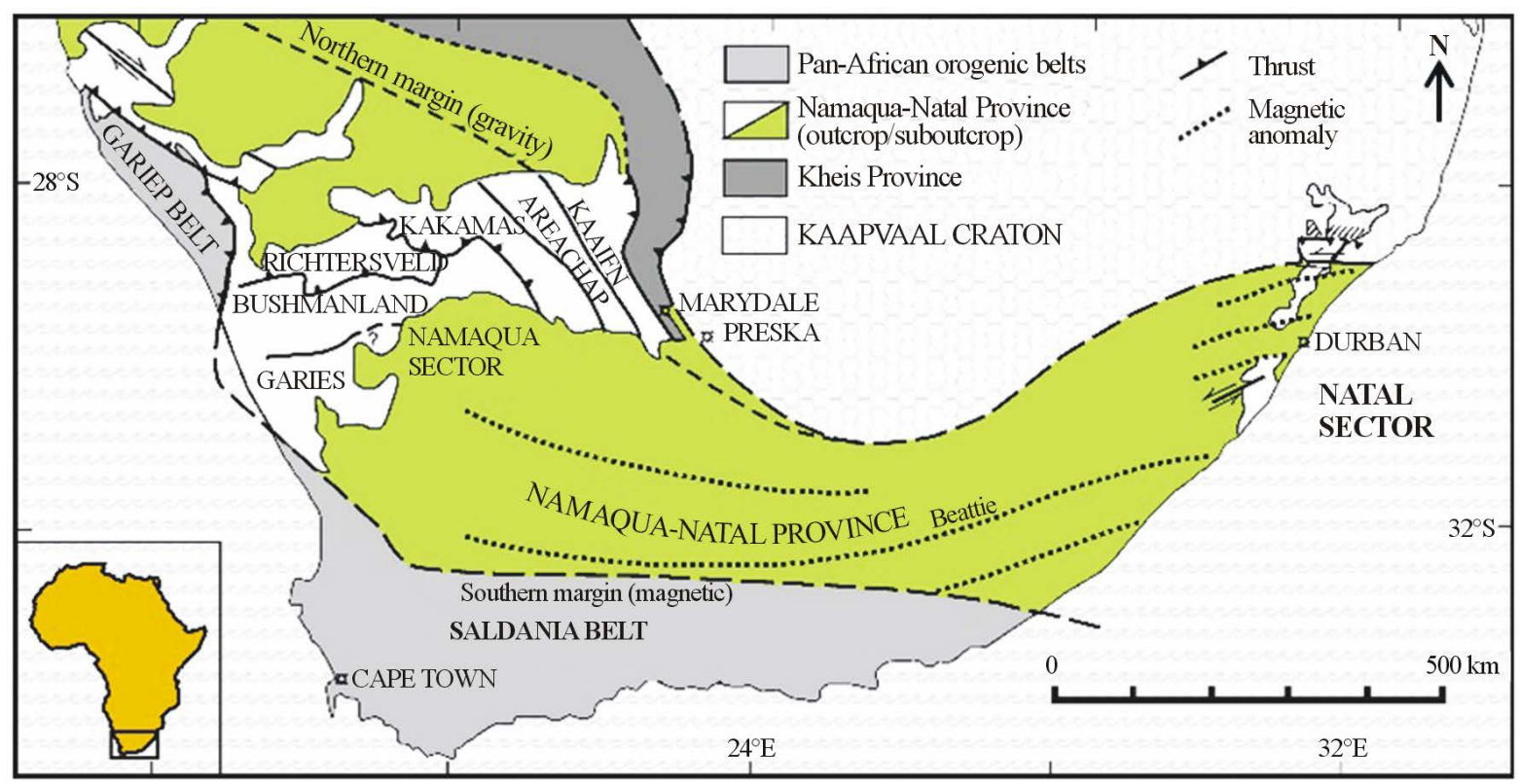

Figure 2. Map of Southern Africa showing Namaqua-Natal Province (modified after Cornell et al. 2006). 
Table 1. Specifications of ASTER data.

\begin{tabular}{ccccc}
\hline System & Band & Spectral range $(\boldsymbol{\mu M})$ & Spatial resolution & Radiometric resolution \\
\hline \multirow{2}{*}{ VNIR } & 1 & $0.52-0.60$ & $15 \mathrm{~m}$ & 8 bit \\
& 2 & $0.63-0.69$ & & \\
\hline \multirow{2}{*}{ SWIR } & 3 & $0.78-0.86$ & & \\
& 4 & $1.60-1.70$ & $30 \mathrm{~m}$ & \\
& 5 & $2.145-2.185$ & & \\
& 7 & $2.185-2.225$ & & \\
& 8 & $2.235-2.285$ & & \\
& 9 & $2.295-2.365$ & & \\
& 10 & $2.360-2.430$ & & \\
& 11 & $8.125-8.825$ & & \\
\hline
\end{tabular}

Table 2. Specifications of QB data.

\begin{tabular}{cccc}
\hline Sensor & Description & Resolution & Bandwidth ( $\boldsymbol{\mu m})$ \\
\hline Panchromatic & Panchromatic & $\sim 0.6 \mathrm{~m}$ & $0.45-0.90 \mu \mathrm{m}$ \\
\hline \multirow{2}{*}{ Multispectral } & Band 1 (blue) & $\sim 2.4 \mathrm{~m}$ & $0.45-0.52 \mu \mathrm{m}$ \\
& Band 2 (green) & $\sim 2.4 \mathrm{~m}$ & $0.52-0.60 \mu \mathrm{m}$ \\
& Band 3 (red) & $\sim 2.4 \mathrm{~m}$ & $0.63-0.69 \mu \mathrm{m}$ \\
\hline
\end{tabular}

were further updated with high resolution World View-2 (QB) imagery.

ASTER imageries were processed which includes satellite data import, cross talk correction (ASTER SWIR band number 4 has spectral leakage that influences band 5 and 9), atmospheric correction through log residual method, geometric correction through geo-referencing, removal of noise through image normalization and scaling of the data to increase the interpretability (Figure 3).

In order to improve the radiometric quality and optimization of the QB image for subsequent processing, a series of filters were applied. The preprocessing includes noise reduction, contrast and edge enhancement (Figure 4).

Spectral analyses (Figure 5) were carried out using different bands through various spectral analytical techniques viz. Band Combination, Band Ratio, PCA (Principal Component Analysis) and SAM (Spectral Angle Mapper).

\subsubsection{Band Combination}

Earth's surface features responses in various channels of the ASTER satellite image which produces distinct characteristic signatures that are helpful in identifying the surface lithological and structural features. A combination of three channels can be viewed at an instance by creating False Colour Composite (FCC). Various band combinations were analyzed iteratively to interpret significance of features by combining the channels in VNIR, SWIR and TIR bands. RGB color combinations with high Optimum Index Factor (OIF) and determinants values are expected to have the maximum extractable spectral information since they use bands with the least redundancy in the remote sensing data. Bands 7, 4, 2 in RGB distinguished granite hosted rocks in the study area block. 


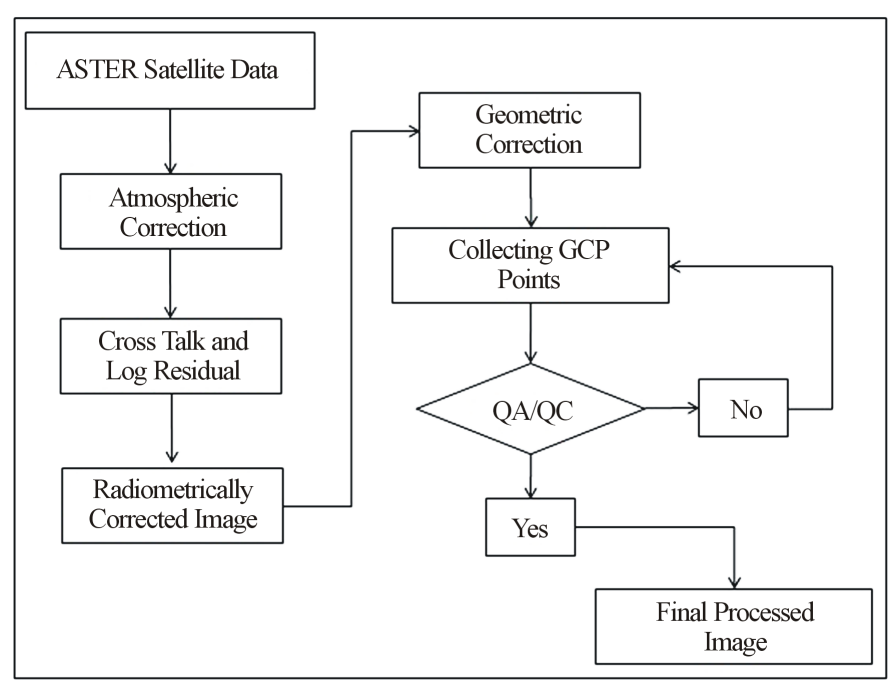

Figure 3. Steps showing ASTER data preprocessing.

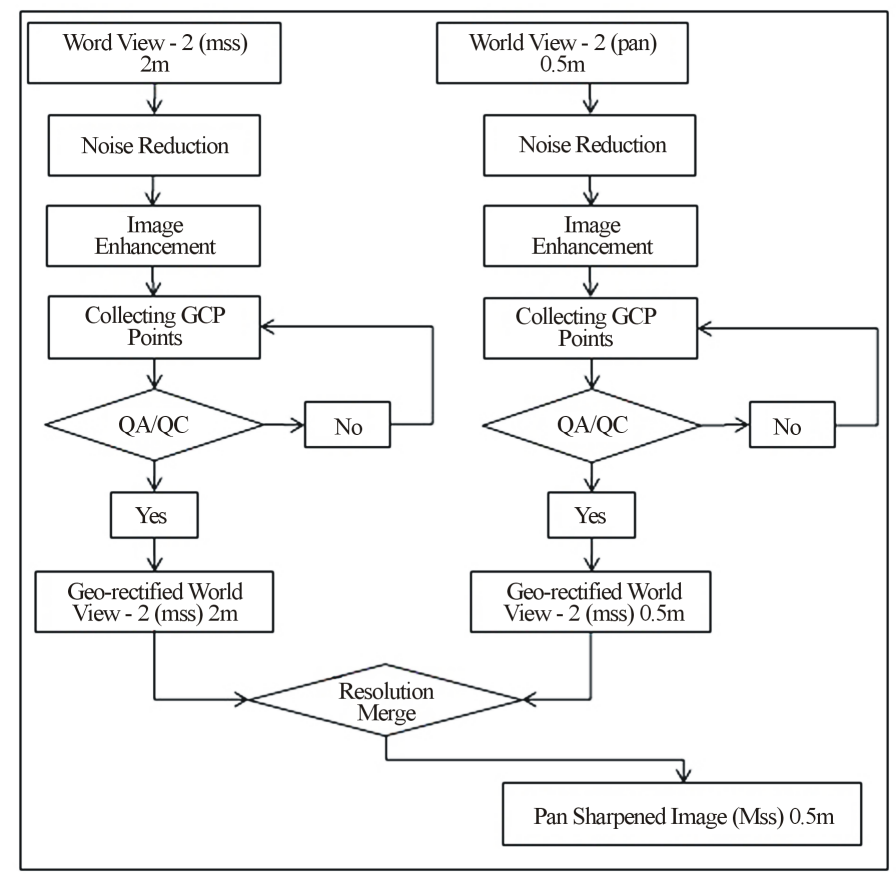

Figure 4. Steps showing QB data preprocessing.

\subsubsection{Band Rationing}

All the minerals have peculiar and significant absorption and reflection characteristic in discrete bandwidths which are diagnostic of its presence. A significant contrast can be achieved through ratio of the bands showing absorption and reflection to generate an output image which is perceived as target mineral. VNIR and SWIR bands of ASTER satellite image are used in various permutations to generate different band ratio combinations. The color composition of R (5/8) G (4/6) B (6/7) showed the occurrence of uranium ore in the study area.

\subsubsection{Principal Component Analysis}

Every feature on the earth's surface is sensed at different magnitude of reflection in different band width in the ASTER dataset. At certain band each of the features show characteristic spectral signature. PCA technique accumulates the characteristic signature of these features into a single component which enable the interpretation 


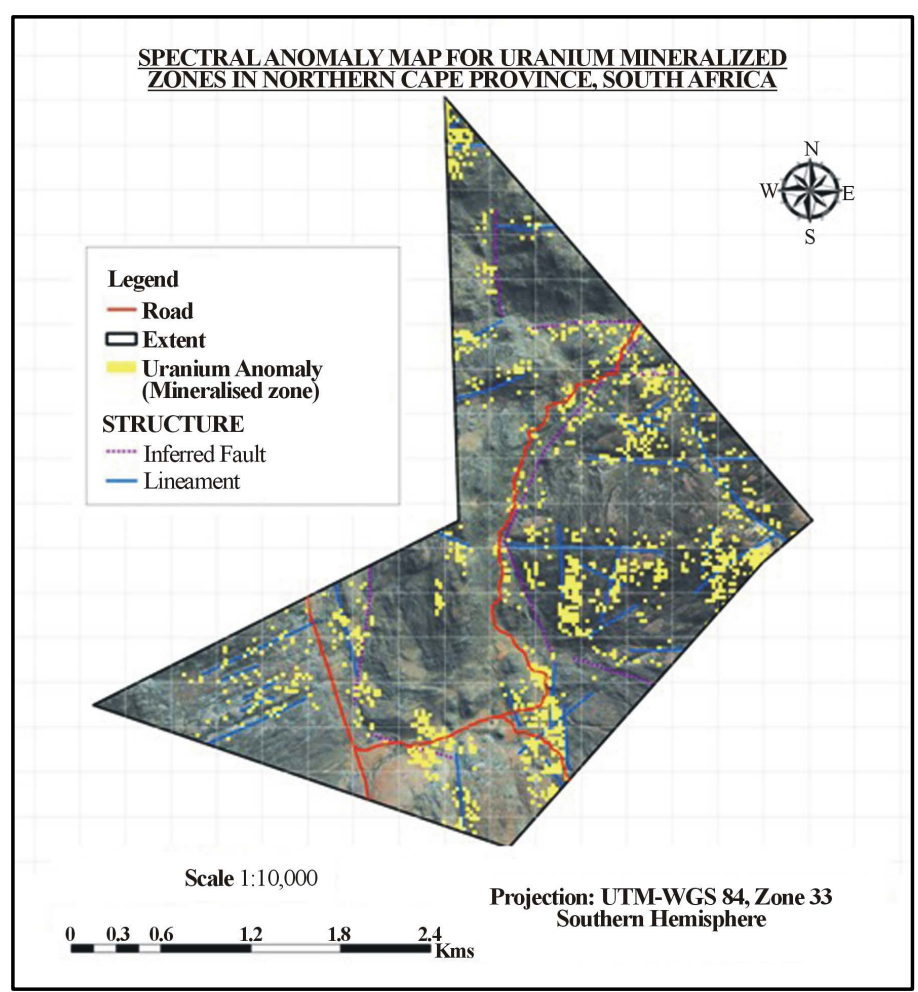

Figure 5. Anomalous signatures of uranium deciphering presence of radioactive material identified from remote sensing studies.

of features as anomalous to the surrounding that renders easy interpretation. PCA transformation is use to produce uncorrelated output bands. PCA bands produce more colorful color composite images than spectral color composite images because the data are uncorrelated. Hence, this technique is efficiently used to identify anomalous signatures which can be correlated to the mineralization. This PCA based analysis has been incorporated in the present study to distinguish the presence of uranium bearing zones.

\subsubsection{Spectral Angle Mapper}

Spectral Angle Mapper is described as physically-based spectral classification that uses n-D angle to match pixels to reference spectra. End member spectra of ASCII files or spectral libraries were used by SAM. SAM compares the angle between the end member spectrum vector and each pixel vector in n-D space. Different end member pixels have been obtained from SAM thereby generating pure end member pixel for uranium hosted rock which were being classified on the basis of spectral reflectance and the geological setting of the area.

Digital Elevation Model (DEM) generated with reference to ASTER images and its derivatives have also been considered as reference for structural interpretation.

\subsection{Geological Mapping}

Outputs of remote sensing data were refined and updated by geological field observations to bring out a clear picture of the tectonic settings controlling the uranium mineralization in the study area. Four significant litho units were identified and mapped viz. the recent alluvium, amphibolite schist, concordia granite and undifferentiated granite (Figure 6). Majority of the study area is dominated by concordia granite formed during the geological ages of Proterozoic epoch. These concordia granite bodies formed the highly-dissected structural hills which were intruded by pegmatite veins hosting uranium mineralization.

Well developed E-W oriented lineations were identified in the uranium hosted concordia granite bodies. Foliations are poor to indistinct but the rocks are highly fractured and sheared which indicates the tectonic implications of the area. This also reveals that the zones of high lineament density are represented by the altered minerals of iron, kaolinite, calcite etc. This correlation thus suggests that primary mineralization of uranium is 


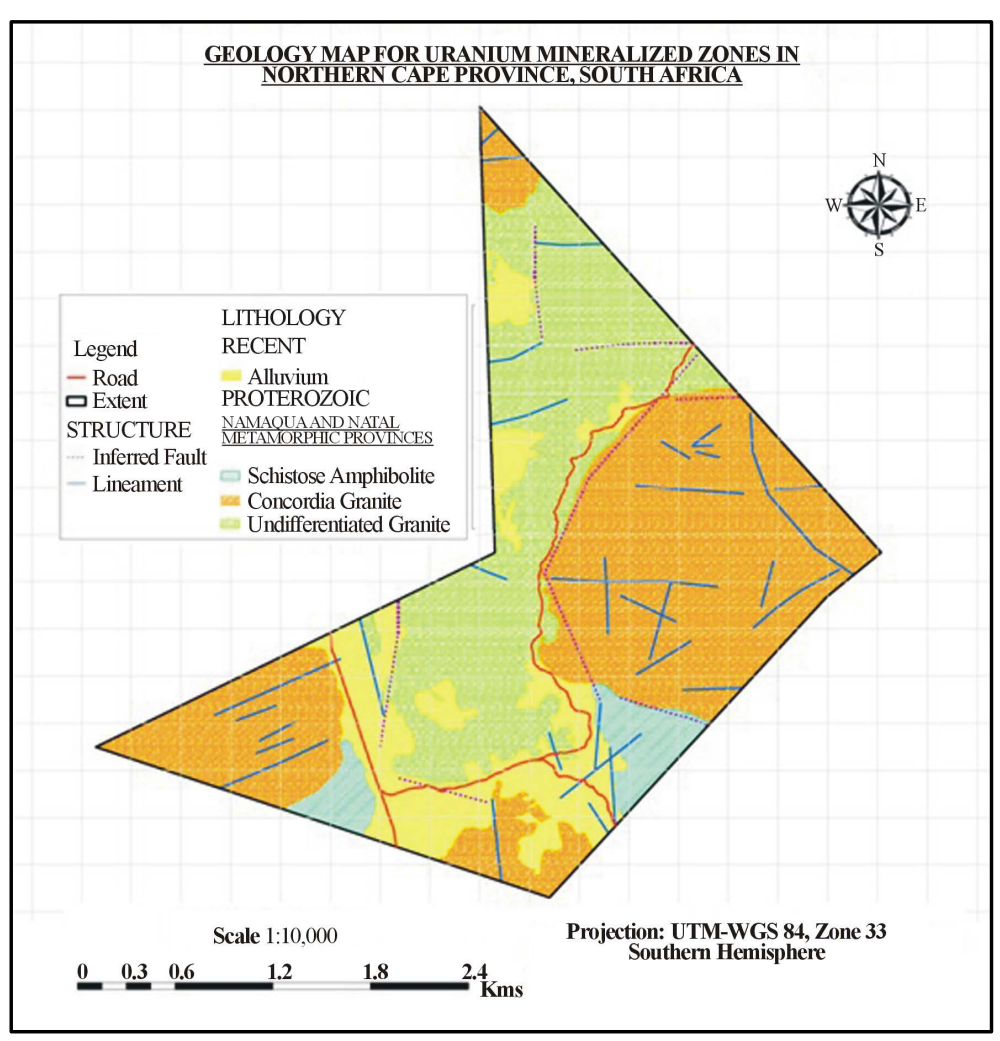

Figure 6. Geological map of the study area.

tectonically controlled in the study area.

\subsection{Geophysical Studies}

Geophysical studies viz magnetic and radiometric surveys were carried out in the identified probable zones. These zones were identified through remote sensing studies and geological mapping of the study area.

\subsubsection{Magnetic Survey}

The magnetic method is based on the measurement of earth's induced magnetic field and magnetic anomalies that are generally caused by subsurface susceptibility contrasts. As the magnetic susceptibility varies significantly between different rock types, it helps in differentiation of sedimentary rocks from igneous rocks. Magnetic survey not only helps in deducing subsurface lithologies but also maps the subsurface structures that indirectly give support to identify uranium mineralization. As remote sensing studies show uranium signatures along surface fractures, thus one needs to understand the extent of these fractures to identify the subsurface uranium mineralization.

Magnetic survey was carried out along the pre defined traverses along N-S direction using Proton Precession Magnetometer with $1 \mathrm{nT}$ (nano Tesla) sensitivity. Data were collected at $100 \mathrm{~m}$ traverse line interval with stations at $10 \mathrm{~m}$ interval on each traverse. Simultaneously a base magnetometer set-up in a non-anomalous magnetic region was used to record the diurnal variations (observe the magnetic storms etc.) at regular time intervals from the start of the survey until the completion of the survey. The average diurnal variation value was taken as the reference to obtain the residual induced field, which is the characteristic contribution from the geology and tectonic settings of the area under study. The magnetic data reduction has resulted in higher resolution of the magnetic picture by facilitating the drawing contours of smaller intervals, by which subdued features of mineralization are brought to sharper focus.

The process of analytical signal (Figure 7) helped in transforming the magnetic anomaly into zones of structural disturbances while the calculation of vertical derivative was undertaken to enhance the high frequency component which demarcates the sub-surface shallow features controlling uranium mineralization. 


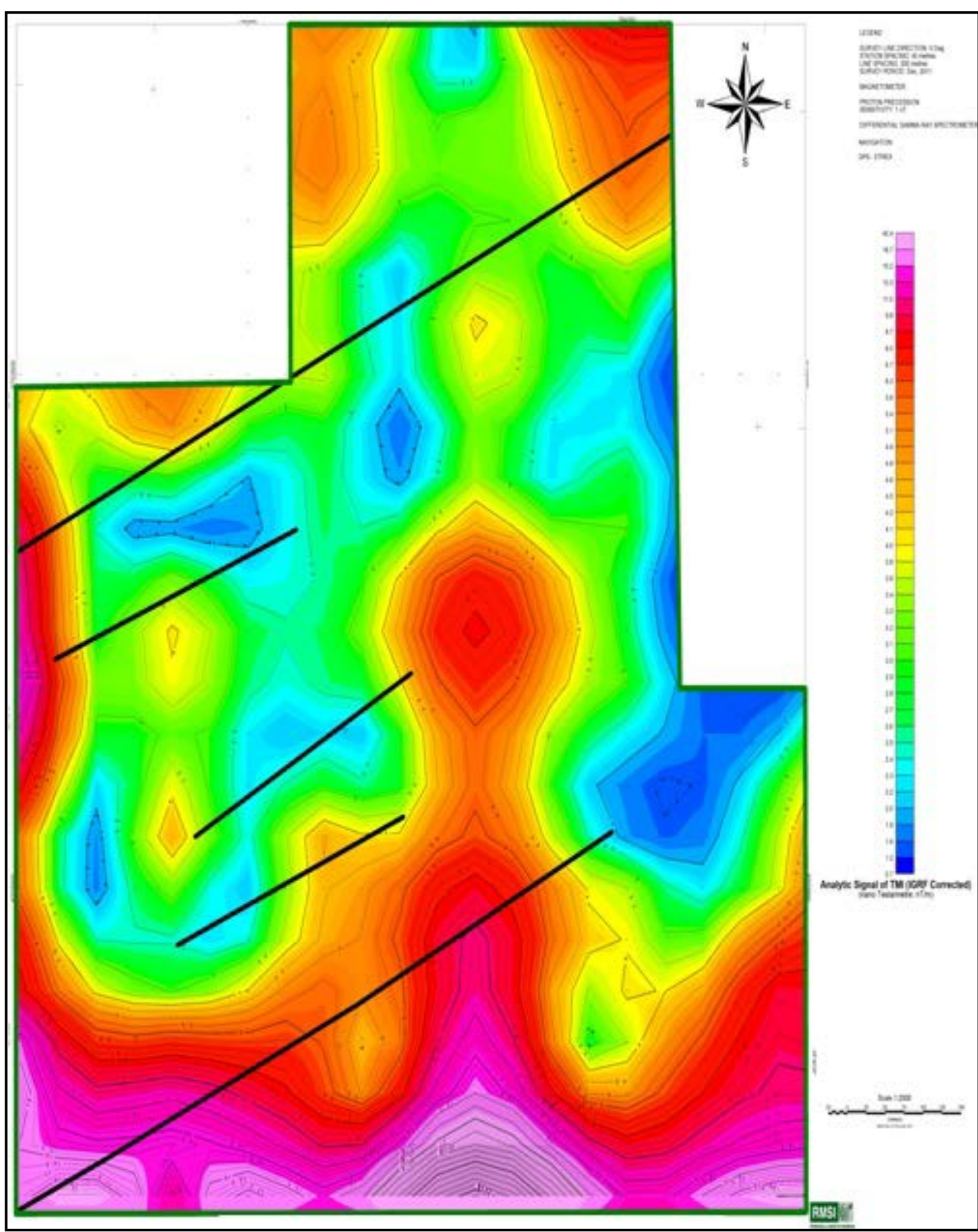

Figure 7. Analytical Signal Map (IGRF Corrected) of zone-I revealing areas of structural disturbances.

\subsubsection{Radiometric Survey}

The radiometric survey is for measuring the concentration of uranium, thorium and potassium in the rocks of the area. The average abundance of uranium, thorium and potassium in the earth's crust (upper part) is about $2 \mathrm{ppm}$, 8 ppm and 1.2\% respectively. Differential Gamma Ray Spectrometer was used to collect the radiometric data at the same stations and traverses selected for the magnetic data collection. The collected data were processed to obtain the spectral ratio outputs of U/Th, U/K, Th/K (Figure 8) which was calculated to define anomalous sites of radioactive altered zones. The processed data thus obtained was in ppm for $\mathrm{U}$ and Th concentration and in \% for K concentration.

\subsection{Geochemical Studies}

As the geological field studies showed that the entire study area hosts uranium bearing granitic rocks, this urges 


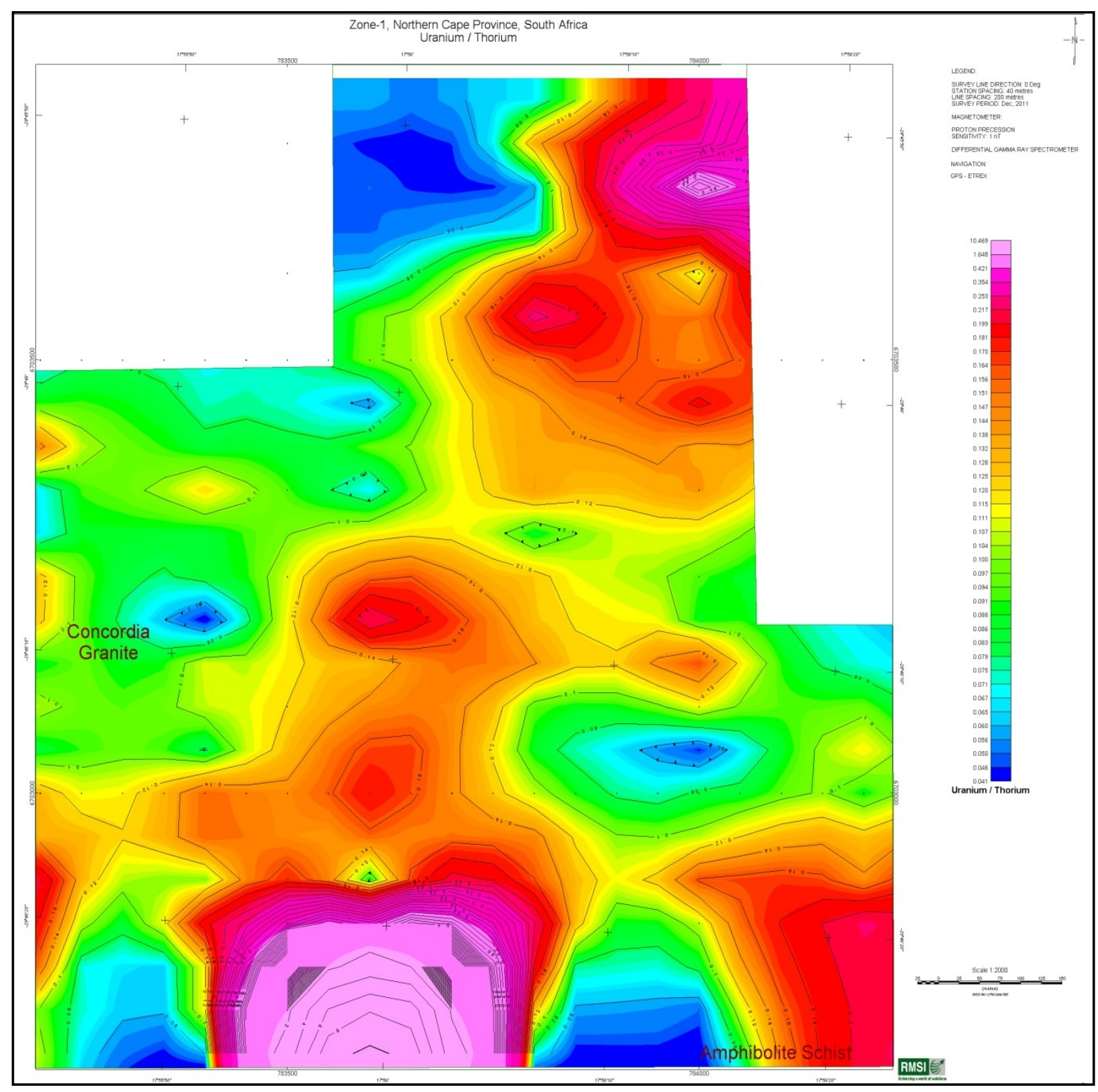

Figure 8. U/Th ratio map for probable zone-I which defines the sites of radioactive mineralization.

the need of sampling to identify the high ore concentration zones and their trend in the probable areas. Rock chip samples were collected at the points (Figure 9) with stronger radiometric anomaly identified from radiometric survey. 108 samples were collected for geochemical analysis which was further plotted on the geological data and structural units to define geochemical anomalies of the area. The collected samples were processed and analyzed for uranium (U in ppm) and other associated elements like thorium (Th in ppm) and potassium (K in \%) using XRF method.

\section{Results}

Remote sensing, geological, geochemical and geophysical data was integrated in a stepwise manner to define the probable mineralized zones of uranium and associated minerals in the project area.

Remote sensing signatures were updated by field geological data [4] to prioritize areas for geophysical and geochemical studies. Two probable zones viz. Zone-I (3.79 sq km) and Zone-II (1.27 sq km) were identified based on anomalous signatures. 


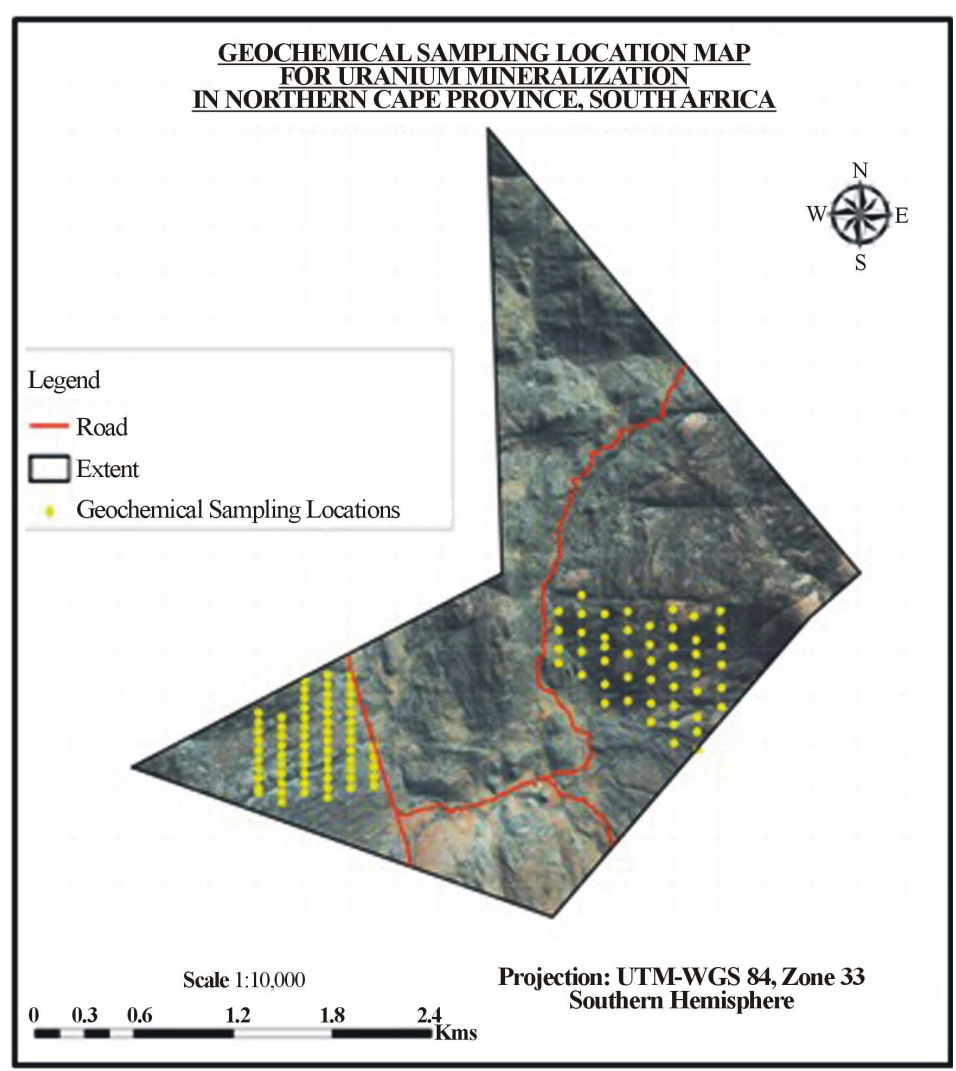

Figure 9. Geochemical sampling locations for Uranium mineralization in the allotted area.

In Zone I high magnetic intensity zones were marked along NW-SE trend in north western, central and southern part. Clustered high magnetic areas were noticed in NW corner of the zone. A low intensity area was found in central part of the block trending along E-W direction. In Zone II high magnetic intensity zones were noticed in the north western and north eastern part trending along N-S direction connected by E-W trending low intensity features.

Radiometric study shows that uranium concentration is mainly confined to NE part of the zone I trending along NE-SW direction and are confined to the western margin of the area with NS trend in zone II. The results of the radiometric survey were presented in Table 3.

Geochemical analysis shows that the U-308 values ranges from 9 ppm to 21 ppm with some high values of 37, 77 and 93 ppm; Th values ranges from 28 ppm to 100 ppm with some high values of 161, 191, 199 and 252; and $\mathrm{K}$ values ranges from $<0.2 \%$ to $7.12 \%$ (Table 4 ).

\section{Discussion}

Remote sensing satellite data, geological, geophysical and geochemical survey datasets were integrated and interpreted to define the mineralized zones of radioactive uranium and its associated minerals. The outputs obtained from remote sensing studies helped in finding the ore prospect anomalous zones. As per the geological settings of the area, uranium mineralization is controlled by the dominant litho unit i.e. concordia granite which hosts uranium and its associated mineralization. The mineralization was found to be controlled by structural elements viz. faults, fissures, joints etc. trending along NE-SW direction.

Rock chip samples from sheared uranium hosted granite showed high anomalous value of uranium and other associated mineralization which is controlled by fracture/fault system.

Analytical signal magnetic output revealed the low intensity zones corroborating with the structural fabric of the area while spectrometric data provided the information on anomalous concentration of uranium within the study area. 
Table 3. Radiometric data — concentration of $\mathrm{U}$ and $\mathrm{Th}$ in ppm and $\mathrm{K}$ in \%.

\begin{tabular}{|c|c|c|c|c|c|c|c|c|c|c|c|}
\hline S. No & $\underset{(\mathbf{p p m})}{\mathrm{U}}$ & $\begin{array}{c}\text { Th } \\
\text { (ppm) }\end{array}$ & $\begin{array}{c}\text { K } \\
(\%)\end{array}$ & S. No & $\underset{(\mathbf{p p m})}{\mathbf{U}}$ & $\begin{array}{c}\text { Th } \\
\text { (ppm) }\end{array}$ & $\begin{array}{c}\mathrm{K} \\
(\%)\end{array}$ & S. No & $\begin{array}{c}\mathrm{U} \\
(\mathbf{p p m})\end{array}$ & $\begin{array}{c}\text { Th } \\
\text { (ppm) }\end{array}$ & $\begin{array}{c}\mathbf{K} \\
(\%)\end{array}$ \\
\hline 1 & 13 & 66 & & 83 & 3 & 51 & & 165 & 6 & 30 & 5.4 \\
\hline 2 & 16 & 56 & & 84 & 10 & 48 & 5.1 & 166 & 9 & 39 & 4.8 \\
\hline 3 & 12 & 44 & 5.9 & 85 & 5 & 53 & & 167 & 10 & 160 & \\
\hline 4 & 9 & 51 & 5.8 & 86 & 9 & 48 & 5.6 & 168 & 26 & 61 & \\
\hline 5 & 15 & 58 & 5.5 & 87 & 6 & 57 & & 169 & 11 & 39 & 4.4 \\
\hline 6 & 13 & 82 & & 88 & 11 & 53 & & 170 & 8 & 48 & 5.4 \\
\hline 7 & 21 & 92 & & 89 & 41 & 62 & 4.1 & 171 & 10 & 96 & 5.9 \\
\hline 8 & 28 & 68 & 4.8 & 90 & 16 & 26 & 4.5 & 172 & 5 & 91 & \\
\hline 9 & 24 & 108 & & 91 & 18 & 35 & 4.9 & 173 & 13 & 96 & \\
\hline 10 & 25 & 186 & & 92 & 11 & 46 & & 174 & 5 & 57 & \\
\hline 11 & 32 & 80 & & 93 & 6 & 48 & 5.4 & 175 & 3 & 66 & \\
\hline 12 & 13 & 82 & & 94 & 8 & 47 & & 176 & 11 & 126 & \\
\hline 13 & 9 & 45 & 5.8 & 95 & 8 & 67 & & 177 & 10 & 97 & \\
\hline 14 & 8 & 64 & & 96 & 13 & 52 & & 178 & 3 & 78 & \\
\hline 15 & 7 & 75 & & 97 & 8 & 34 & 5.7 & 179 & 7 & 57 & \\
\hline 16 & 23 & 57 & 5.9 & 98 & 7 & 58 & & 180 & 5 & 128 & \\
\hline 17 & 19 & 87 & & 99 & 5 & 58 & & 181 & 5 & 107 & \\
\hline 18 & 15 & 99 & & 100 & 7 & 37 & 5.1 & 182 & 3 & 67 & \\
\hline 19 & 10 & 40 & 5.5 & 101 & 4 & 52 & 5.9 & 183 & 4 & 67 & \\
\hline 20 & 10 & 120 & & 102 & 3 & 45 & & 184 & 3 & 47 & \\
\hline 21 & 5 & 62 & 5.7 & 103 & 5 & 25 & 5.8 & 185 & 10 & 55 & \\
\hline 22 & 5 & 54 & 5.9 & 104 & 5 & 29 & & 186 & 4 & 54 & \\
\hline 23 & 16 & 70 & & 105 & 7 & 48 & 5.4 & 187 & 3 & 58 & \\
\hline 24 & 6 & 66 & & 106 & 6 & 41 & 5.7 & 188 & 7 & 99 & \\
\hline 25 & 12 & 58 & & 107 & 6 & 41 & & 189 & 20 & 94 & \\
\hline 26 & 10 & 53 & 5.1 & 108 & 5 & 48 & & 190 & 17 & 47 & \\
\hline 27 & 9 & 65 & & 109 & 7 & 33 & 4.9 & 191 & 10 & 65 & \\
\hline 28 & 5 & 52 & 5.8 & 110 & 17 & 42 & 2.5 & 192 & 11 & 53 & 5.6 \\
\hline 29 & 7 & 64 & 5.9 & 111 & 7 & 19 & 4 & 193 & 24 & 194 & \\
\hline 30 & 8 & 76 & & 112 & 5 & 27 & 5.5 & 194 & 9 & 103 & \\
\hline 31 & 6 & 70 & & 113 & 6 & 40 & & 195 & 18 & 119 & \\
\hline 32 & 20 & 73 & & 114 & 6 & 26 & 5.5 & 196 & 8 & 124 & \\
\hline 33 & 24 & 85 & & 115 & 7 & 45 & & 197 & 11 & 76 & 5.4 \\
\hline 34 & 7 & 63 & & 116 & 4 & 32 & 5.1 & 198 & 5 & 40 & 5.3 \\
\hline 35 & 8 & 57 & & 117 & 7 & 57 & & 199 & 7 & 61 & 5.2 \\
\hline 36 & 8 & 112 & & 118 & 5 & 52 & & 200 & 5 & 24 & 4.8 \\
\hline 37 & 5 & 72 & & 119 & 7 & 58 & & 201 & 3 & 35 & 5.5 \\
\hline 38 & 9 & 75 & & 120 & 4 & 69 & 5.6 & 202 & 3 & 38 & \\
\hline 39 & 6 & 57 & & 121 & 5 & 36 & 5.4 & 203 & 5 & 34 & \\
\hline 40 & 9 & 82 & & 122 & 6 & 29 & 4.9 & 204 & 3 & 40 & \\
\hline 41 & 10 & 79 & & 123 & 7 & 46 & 5 & 205 & 7 & 59 & \\
\hline 42 & 16 & 86 & & 124 & 14 & 75 & & 206 & 5 & 28 & 4.7 \\
\hline
\end{tabular}




\section{Continued}

\begin{tabular}{|c|c|c|c|c|c|c|c|c|c|c|c|}
\hline 43 & 14 & 92 & & 125 & 4 & 46 & 5.9 & 207 & 7 & 38 & 5.7 \\
\hline 44 & 29 & 37 & 4.6 & 126 & 7 & 40 & 4.8 & 208 & 8 & 49 & \\
\hline 45 & 21 & 41 & 4.9 & 127 & 5 & 23 & 4.8 & 209 & 3 & 11 & \\
\hline 46 & 12 & 31 & 4.3 & 128 & 8 & 46 & 5.8 & 210 & 6 & 50 & 5.6 \\
\hline 47 & 17 & 23 & 3.6 & 129 & 3 & 40 & 5.4 & 211 & 20 & 69 & \\
\hline 48 & 12 & 15 & 3.3 & 130 & 9 & 101 & & 212 & 21 & 106 & \\
\hline 49 & 17 & 30 & 4 & 131 & 12 & 64 & & 213 & 57 & 98 & \\
\hline 50 & 26 & 46 & 5.4 & 132 & 3 & 102 & & 214 & 20 & 110 & \\
\hline 51 & 14 & 25 & 4.5 & 133 & 3 & 137 & & 215 & 11 & 51 & \\
\hline 52 & 15 & 22 & 3.4 & 134 & 13 & 144 & & 216 & 6 & 112 & \\
\hline 53 & 15 & 28 & 3.7 & 135 & 9 & 87 & 4.3 & 217 & 12 & 57 & \\
\hline 54 & 21 & 45 & 4.3 & 136 & 17 & 183 & & 218 & 9 & 60 & \\
\hline 55 & 15 & 35 & 4.3 & 137 & 3 & 65 & & 219 & 15 & 88 & \\
\hline 56 & 13 & 43 & 5.2 & 138 & 9 & 62 & & 220 & 12 & 61 & \\
\hline 57 & 12 & 39 & 5.9 & 139 & 4 & 50 & & 221 & 3 & 40 & 5.6 \\
\hline 58 & 13 & 36 & 5.4 & 140 & 7 & 72 & & 222 & 9 & 48 & 5.6 \\
\hline 59 & 19 & 55 & 4.6 & 141 & 13 & 143 & & 223 & 8 & 88 & 5.7 \\
\hline 60 & 13 & 56 & 5.2 & 142 & 15 & 98 & & 224 & 6 & 62 & 5.2 \\
\hline 61 & 23 & 103 & & 143 & 5 & 62 & & 225 & 3 & 27 & 4.8 \\
\hline 62 & 13 & 41 & & 144 & 5 & 53 & & 226 & 3 & 42 & 5.7 \\
\hline 63 & 9 & 55 & & 145 & 14 & 142 & 5.6 & 227 & 7 & 22 & \\
\hline 64 & 12 & 56 & & 146 & 11 & 108 & 4.1 & 228 & 8 & 54 & \\
\hline 65 & 11 & 66 & 5.9 & 147 & 13 & 90 & & 229 & 3 & 142 & \\
\hline 66 & 13 & 90 & & 148 & 5 & 51 & 4.3 & 230 & 8 & 69 & 5.9 \\
\hline 67 & 14 & 88 & & 149 & 7 & 29 & 4.1 & 231 & 3 & 23 & \\
\hline 68 & 9 & 52 & & 150 & 10 & 181 & & 232 & 4 & 44 & \\
\hline 69 & 7 & 67 & & 151 & 11 & 39 & 4.3 & 233 & 6 & 24 & 5.4 \\
\hline 70 & 9 & 76 & & 152 & 7 & 45 & & 234 & 4 & 37 & \\
\hline 71 & 8 & 47 & & 153 & 4 & 29 & 5.9 & 235 & 3 & 37 & \\
\hline 72 & 5 & 53 & & 154 & 6 & 23 & 5.5 & 236 & 7 & 51 & 5.2 \\
\hline 73 & 5 & 49 & & 155 & 7 & 48 & 5.6 & 237 & 20 & 98 & \\
\hline 74 & 6 & 59 & 5.8 & 156 & 4 & 41 & & 238 & 6 & 35 & \\
\hline 75 & 5 & 45 & 5.9 & 157 & 7 & 29 & 5.5 & 239 & 5 & 33 & \\
\hline 76 & 26 & 58 & & 158 & 38 & 9 & 5.6 & 240 & 4 & 25 & 4.7 \\
\hline 77 & 6 & 38 & 5 & 159 & 47 & 7 & 3.8 & 241 & 3 & 20 & 5.2 \\
\hline 78 & 12 & 53 & & 160 & 3 & 41 & 4.5 & 242 & 8 & 65 & 5.5 \\
\hline 79 & 5 & 45 & 5.4 & 161 & 3 & 37 & 5.3 & 243 & 10 & 72 & \\
\hline 80 & 3 & 37 & & 162 & 7 & 44 & 5.9 & 244 & 10 & 157 & \\
\hline 81 & 7 & 61 & & 163 & 9 & 38 & 5.6 & 245 & 8 & 136 & \\
\hline 82 & 8 & 51 & 5.8 & 164 & 5 & 38 & 5.9 & & & & \\
\hline
\end{tabular}


Table 4. Radiometric data—concentration of $\mathrm{U}$ and $\mathrm{Th}$ in $\mathrm{ppm}$ and $\mathrm{K}$ in \%.

\begin{tabular}{|c|c|c|c|c|c|c|c|}
\hline Sample ID & $\begin{array}{l}\text { U-308 } \\
\text { (ppm) }\end{array}$ & $\begin{array}{c}\text { Th } \\
\text { (ppm) }\end{array}$ & K (\%) & Sample ID & $\begin{array}{l}\text { U-308 } \\
\text { (ppm) }\end{array}$ & $\begin{array}{c}\text { Th } \\
\text { (ppm) }\end{array}$ & K (\%) \\
\hline S1 & 9 & 28 & $<0.2$ & S55 & 10 & 13 & 3.45 \\
\hline S2 & 9 & 37 & $<0.2$ & S56 & 9 & 17 & 3.26 \\
\hline S3 & 9 & 41 & $<0.2$ & S57 & 9 & 31 & 4.48 \\
\hline S4 & 9 & 21 & $<0.2$ & S58 & 14 & 252 & 4.92 \\
\hline S5 & 21 & 66 & $<0.2$ & S59 & 9 & 24 & 4.65 \\
\hline S6 & 9 & 9 & $<0.2$ & S60 & 9 & 27 & 3.56 \\
\hline S7 & 9 & 26 & $<0.2$ & S61 & 9 & 28 & 4.66 \\
\hline S8 & 9 & 85 & $<0.2$ & S62 & 10 & 21 & 2.70 \\
\hline S9 & 16 & 96 & $<0.2$ & S63 & 12 & 59 & 2.61 \\
\hline S10 & 9 & 31 & $<0.2$ & S64 & 13 & 98 & 5.34 \\
\hline S11 & 9 & 9 & $<0.2$ & S65 & 9 & 36 & 4.19 \\
\hline S12 & 9 & 29 & $<0.2$ & S66 & 93 & 75 & 4.62 \\
\hline S13 & 10 & 44 & $<0.2$ & S67 & 9 & 21 & 4.06 \\
\hline S14 & 37 & 70 & $<0.2$ & S68 & 12 & 78 & 4.63 \\
\hline S15 & 9 & 31 & $<0.2$ & S69 & 9 & 40 & 4.45 \\
\hline S16 & 9 & 35 & $<0.2$ & S70 & 9 & 21 & 0.87 \\
\hline S17 & 9 & 38 & $<0.2$ & S71 & 9 & 19 & 1.05 \\
\hline S18 & 9 & 16 & $<0.2$ & S72 & 9 & 9 & 3.93 \\
\hline S19 & 9 & 35 & $<0.2$ & S73 & 10 & 19 & 3.95 \\
\hline S20 & 18 & 34 & $<0.2$ & S74 & 14 & 56 & 4.38 \\
\hline S21 & 9 & 62 & $<0.2$ & S75 & 9 & 9 & 2.65 \\
\hline S22 & 9 & 12 & $<0.2$ & S76 & 9 & 16 & 3.49 \\
\hline S23 & 10 & 41 & $<0.2$ & S77 & 14 & 75 & 4.04 \\
\hline S24 & 9 & 33 & $<0.2$ & S78 & 77 & 72 & 7.12 \\
\hline S25 & 17 & 56 & $<0.2$ & S79 & 12 & 195 & 5.31 \\
\hline S26 & 9 & 16 & $<0.2$ & S80 & 9 & 13 & 3.97 \\
\hline S27 & 9 & 18 & $<0.2$ & S81 & 9 & 23 & 4.48 \\
\hline S28 & 9 & 19 & $<0.2$ & S82 & 9 & 48 & 3.12 \\
\hline S29 & 9 & 12 & $<0.2$ & S83 & 9 & 12 & 2.40 \\
\hline S30 & 9 & 19 & $<0.2$ & S84 & 9 & 9 & 2.73 \\
\hline S31 & 9 & 9 & $<0.2$ & S85 & 9 & 30 & 1.00 \\
\hline S32 & 9 & 10 & $<0.2$ & S86 & 9 & 16 & 3.37 \\
\hline S33 & 13 & 18 & $<0.2$ & S87 & 9 & 9 & 5.53 \\
\hline S34 & 9 & 16 & $<0.2$ & S88 & 9 & 9 & 2.81 \\
\hline S35 & 12 & 37 & $<0.2$ & S89 & 9 & 9 & 3.42 \\
\hline S36 & 10 & 17 & $<0.2$ & S90 & 9 & 19 & 3.48 \\
\hline S37 & 19 & 199 & $<0.2$ & S91 & 13 & 16 & 3.10 \\
\hline S38 & 15 & 161 & $<0.2$ & S92 & 10 & 20 & 3.16 \\
\hline S39 & 9 & 26 & $<0.2$ & S93 & 10 & 67 & 3.64 \\
\hline S40 & 10 & 34 & $<0.2$ & S94 & 12 & 100 & 4.56 \\
\hline S41 & 9 & 9 & $<0.2$ & S95 & 9 & 11 & 3.24 \\
\hline S42 & 13 & 70 & $<0.2$ & S96 & 9 & 35 & 3.43 \\
\hline S43 & 14 & 37 & $<0.2$ & S97 & 9 & 12 & 3.28 \\
\hline S44 & 9 & 10 & $<0.2$ & S98 & 9 & 17 & 3.64 \\
\hline S45 & 9 & 12 & $<0.2$ & S99 & 9 & 20 & 3.47 \\
\hline S46 & 9 & 25 & $<0.2$ & $\mathrm{~S} 100$ & 9 & 16 & 3.52 \\
\hline S47 & 9 & 12 & $<0.2$ & S101 & 9 & 22 & 3.23 \\
\hline S48 & 9 & 13 & $<0.2$ & S102 & 9 & 18 & 3.64 \\
\hline S49 & 10 & 15 & $<0.2$ & S103 & 9 & 10 & 2.87 \\
\hline S50 & 13 & 95 & $<0.2$ & S104 & 9 & 18 & 3.60 \\
\hline S51 & 10 & 24 & 3.32 & S105 & 9 & 20 & 3.73 \\
\hline S52 & 10 & 10 & 3.72 & S106 & 10 & 28 & 4.01 \\
\hline S53 & 9 & 17 & 3.45 & S107 & 9 & 16 & 3.64 \\
\hline S54 & 15 & 24 & 4.46 & S108 & 9 & 10 & 3.22 \\
\hline
\end{tabular}


The above integrated studies reveal that uranium and its associated mineralization are mainly controlled by structural setting of the area. It is clearly observed from the spectrometric/radiometric data that high concentration uranium zones are occupied along the structural zones which are identified by magnetic analytical signal outputs. This is also supported by the geochemical analysis outputs that are mainly controlled by fracture/fault system. Thus obtained geophysical and geochemical datasets indicate that the grade is not continuous on the surface however the average concentrations are fairly good which may be an indication of better concentration at sub-surface rock basement. Figure 10 shows integrated studies for uranium of zone-I.

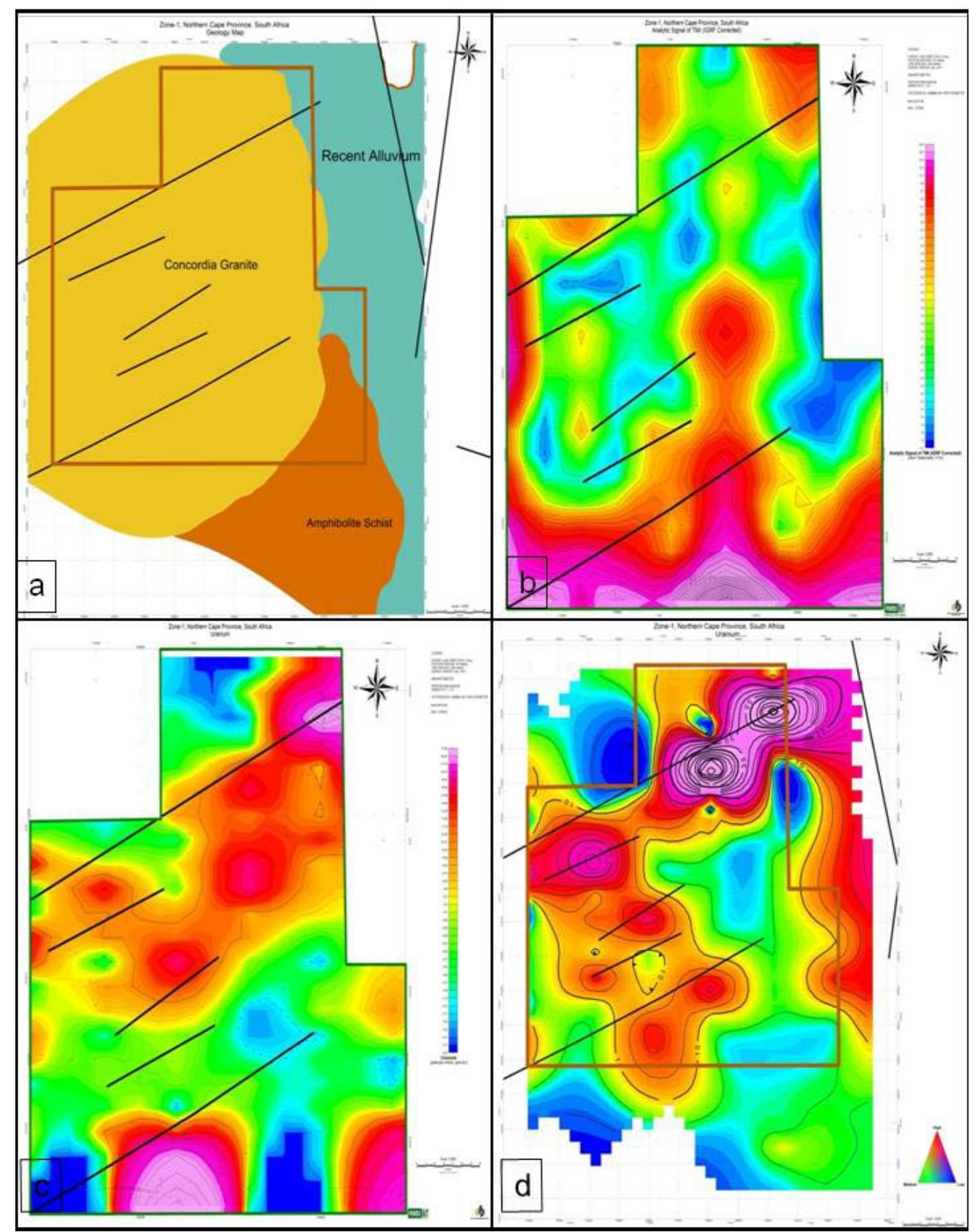

Figure 10. Integrated studies for defining uranium zones of mineralization in zone-I. (a) Represents the geological setting highlighting the structural units along the lithological formation of concordia granite hosting uranium ore; (b) Magnetic analytical map showing the areas of low magnetic zones revealing zones of highly structural disturbances; (c) Uranium (in ppm) contour map showing areas of high concentration of anomalous radioactive values obtained from spectrometric datasets; and (d) Contour map of uranium concentration depicted from geochemical analysis. 


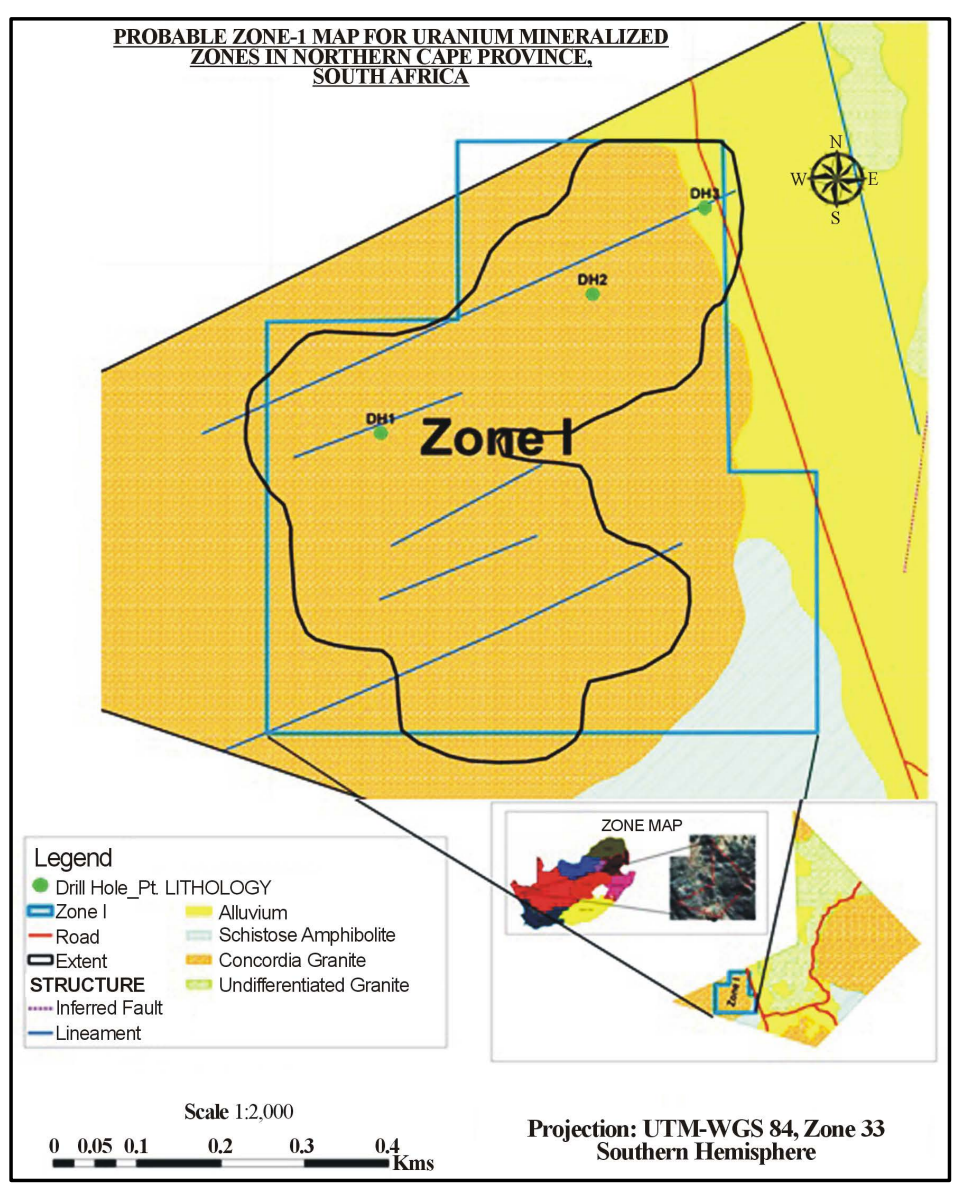

Figure 11. Proposed zone and drill hole locations.

\section{Conclusions}

The study involved a multidisciplinary integrated approach for uranium exploration. The methodology involved satellite remote sensing based spectral studies supplemented by geophysical studies, field geological investigations and geochemical sampling/analysis. Each technique supplemented the other, leading to increased confidence in interpretations at every stage. Each stage of study helped prioritization of target for subsequent stage of investigation. The final conclusions on the study were drawn based on integrated analysis and interpretation of all modes of investigation/study. The multi-stage study and reduced exploration risk helped in making bigger investment decisions on the project.

Such a multi-disciplinary approach involving remote sensing, geochemical and geophysical technology assisted in deciphering zones of uranium mineralization.

The present study successfully helped in defining two major zones of uranium mineralization. Further exploration in the form of exploratory drilling was confined to these zones (Figure 11).

And thus the said integrated methodology is being used widely across the world and has been popularly adopted for its technical and commercial success. Such approach helps in managing investment risks associated with expensive drilling programs and the confidence factor on occurrence of ore body increases substantially.

\section{References}

[1] Said, I.R., Ahmed, A.A.M. and Assran, S.A. (1998) Geological and Geophysical Exploration for Uranium Mineralization in the El-Erediya Prospect Area, Central Eastern Desert, Egypt. Proceedings of the International Conferences on Basement Tectonics, 6, 169-189. http://dx.doi.org/10.1007/978-94-011-5098-9_7

[2] Xu, Y., Liu, D.-C. and Zhang, J.-L. (2008) Ore-Search Information Using ASTER Data in Bashibulake Uranium Deposit Area in Xinjiang. The International Archives of the Photogrammetry, Remote Sensing and Spatial Information 
Sciences, XXXVII (B6b).

[3] Sen, J., Ranganath, N., Rathaiah, Y.V., Sen, D.B. and Kak, S.N. (2009) Petrography and Geochemistry of Uranium Mineralised Precambrian Granitic-Pegmatitic Rocks of Mawlait, West Khasi Hills District, Meghalaya. Journal Geological Society of India, 74, 639-645. http://dx.doi.org/10.1007/s12594-009-0168-8

[4] Shalaby, M.H., Bishta, A.Z., Roz, M.E. and El Zalaky, M.A. (2009) Integration of Geologic and Remote Sensing Studies for the Discovery of Uranium Mineralization in Some Granite Plutons, Eastern Desert, Egypt. JAKU: Earth Science, 21, 1-25.

[5] Haruna, I.V., Orazulike, D.M. and Ofulume, A.B. (2011) Preliminary Geological and Radiometric Studies of Granitoids of Zing-Monkin Area, Adamawa Massif, Ne Nigeria. Global Journal of Geological Sciences, 9.

[6] El Gharbawy, R.I. and El Maadawy, W.M. (2012) Geochemistry of the Uranium-Thorium-Bearing Granitic Rocks and Pegmatites of Wadi Haleifiya Area, Southeastren Sinai, Egypt. Chinese Journal of Geochemistry, 31, 242-259. http://dx.doi.org/10.1007/s11631-012-0573-3

[7] Ramadan, T.M., Ibrahim, T.M., Said, A.D. and Baiumi, M. (2013) Application of Remote Sensing in Exploration for Uranium Mineralization in Gabal El Sela Area, South Eastern Desert, Egypt. The Egyptian Journal of Remote Sensing and Space Sciences, 16, 199-210. http://dx.doi.org/10.1016/j.ejrs.2013.11.001

[8] Pettersson, A. (2008) Mesoproterozoic Crustal Evolution in Southern Africa. Doctoral Thesis A117, Department of Earth Sciences, University of Gothenburg.

[9] Thomas, R.J. (1989) A Tale of Two Tectonic Terranes. South African Journal of Geology, 92, 306-321.

[10] Cornell, D.H., Thomas, R.J., Gibson, R., Moen, H.F.G., Moore, J.M. and Reid, D.L. (2006) Namaqua-Natal Province. In: Johnson, M.R., Anhauesser, C.R. and Thomas, R.J., Eds., Geology of South Africa, Geological Society of South Africa and Council of Geoscience, Pretoria, 325-379. 